\title{
UM OLHAR SOBRE A EXPERIÊNCIA DO PARTO: TRAJETÓRIA, POSSIBILIDADES E REPERCUSSÕES
}

\author{
A look at the experience of childbirth: trajectory, possibilities and repercussions
}

Una mirada sobre la experiencia del parto: trayectoria, posibilidades y repercusiones

Maiumi Souza Cruz FerReira PRISCILA DE LIMA SILVA VANDERSON BARRETo Pereira

\begin{abstract}
Resumo: Esse artigo, produto de uma revisão bibliográfica, teve como propósito descrever o parto enquanto possibilidade de ampliação da consciência da parturiente, destacando a atuação do Gestalt-terapeuta no acompanhamento pré-natal. Para tanto, tomou-se como ponto de partida a trajetória da assistência ao parto e os programas atuais no contexto brasileiro. Os estudos demonstraram que, nos últimos vinte anos, o nascimento tem sido em sua primazia, institucionalizado e masculinizado, o que se justifica pela centralização do poder médico sobre fenômenos femininos e tem como consequência a perda do protagonismo das mulheres na experiência do parto. Os achados evidenciam que a humanização é de extrema importância para fazer frente a essa realidade, pois possibilita que os sujeitos transcendam da heteronomia para a autonomia. Assim, foi possível perceber que o psicólogo Gestalt-terapeuta tem papel fundamental nesse processo, visto que, por meio do cuidado prestado no acompanhamento pré-natal, pode promover saúde mediante a tomada de consciência e o empoderamento das gestantes.
\end{abstract}

Palavras-chave: Parto; Humanização; Psicologia; Gestalt-terapia.

Abstract:This article, product of a literature review aimed to describe childbirth as a possibility of increased awareness of the parturient, highlighting the role of the Gestalt therapist in prenatal care. Therefore, it took as its starting point the trajectory of assistance to child-birth and current programs in the Brazilian context. Studies have demonstrated that in the last twenty years, the birth has been its primacy, institutionalized and masculinized, which is justified by the centralization of medical power over female phenomena and results in the loss of the role of women in childbirth experience. The findings demonstrate that humanization is of extreme importance to face this reality, because it allows the subject transcend from heteronomy to autonomy. Thus it was possible to perceive that the Gestalt therapist psychologist plays a key role in this process because, through the care provided in prenatal care, can promote health through awareness and empowerment of the pregnants.

Keywords:Childbirth; Humanization; Psychology; Gestalt Therapy;

Resumen: En este artículo, producto de una revisión de la literatura destinada a describir el parto como una posibilidad de una mayor conciencia de la madre, destacando el papel del Gestalt terapeuta en la atención prenatal. Por lo tanto, se tomó como punto de partida la trayectoria de la atención y los programas actuales en el contexto brasileñoLos estudios han demostrado que en los últimos veinte años, el nacimiento ha sido su primacía, institucionalizada y masculinizado, que se justifica por la centralización del poder médico sobre fenómenos femeninos y resulta en la pérdida de protagonismo de la mujer en la experiencia del parto. Los resultados muestran que la humanización es de suma importancia para hacer frente a esta realidad, ya que permite a los sujetos trascienden de la heteronomía a la autonomía. Así fue posible ver que el psicólogo Gestalt terapeuta juega un papel clave en este proceso, ya que, a través de la atención recibida en la atención prenatal, puede promover la salud a través de la sensibilización y la potenciación de las mujeres.

Palavras-clave:Parto; La humanización; Psicología; La Gestalt terapia;

\section{Introdução}

Ao longo dos anos, o cuidado com as parturientes vem sofrendo grandes transformações. Métodos cada vez mais tecnológicos e intervencionistas, que garantem ao procedimento rapidez, controle e supostamente segurança, vêm tomando o lugar dos partos naturais, feitos por parteiras ou pessoas de confiança no próprio domicílio.Com a inserção de médicos, predominantemente do sexo masculino, e a medicalização do corpo e dos fenômenos femini- nos, o nascimento passa a ser entendido como uma experiência perigosa e dolorosa, e em face desse status, passam a acontecer hegemonicamente em instituições hospitalares.

O Brasil é, na atualidade, segundo a Organização Mundial de Saúde (OMS), uns dos países com maior índice de cesáreas do mundo, sendo realizados mais da metade dos partos por meio de procedimentos cirúrgicos, embora não exista razão médica ou científica para que esse número seja maior 
que vinte porcento. A visão medicalizante, retira da parturiente o protagonismo do parto e poder de decisão sobre ele, que passa a assumir uma condição de fragilidade e passividade, vulnerabilizando-as e estimulando-as a escolher ou aceitar métodos intervencionistas, sem ao menos conhecer suas possibilidades ou dar-se conta dos benefícios relacionados ao parto natural e a sua fisiologia(Amorim, 2012).

Em face dessas circunstâncias, emerge no Brasil e no mundo, movimentos e programas, como o Programa de Humanização no Pré-natal e Nascimento (PHPN) que foi instituído com a Portaria/GM n.o 569, de 1/6/2000, e a Rede Cegonha (RC) fundada pela portaria MS/GM n ${ }^{\circ} 1.459 / 2011$, ambas instituídas pelo ministério da saúde, que fundamentadas em evidências e na efetividade dos procedimentos, buscam certificar a qualidade da assistência à saúde no processo gravídico puerperal e devolver às mulheres o protagonismo do seu parto, o acesso seguro e de qualidade no pré-natal, e o atendimento acolhedor e humanizado no parto e puerpério em toda rede do Sistema Único de Saúde (Diniz, 2005).

Contudo, percebe-se que a implementação do PHPN, bem como da RC, enfrentam alguns desafios ligados à sua implantação. As principais dificuldades encontradas no SUS relacionam-se a estrutura física hospitalar, que diante da grande demanda, muitas vezes não possuem condições necessárias para se tornar um ambiente acolhedor que respeita a psicofisiologia de cada parto, bem como, melhores condições de trabalho e educação permanente para os profissionais de saúde, de modo que as diretrizes propostas pelos programas façam sentido para eles e a organização do hospital se torne efetivamente voltada às necessidades das gestantes e parturientes(Dias e Domingues, 2005).

Tais programas possibilitam a expansão do cuidado e a inserção de novas especialidades, propiciando assim, a introdução de psicólogos na assistência pré-natal, tendo nesse contexto o papel fundamental de estimular a tomada de consciência e o fortalecimento das mulheres, para que elas retomem o domínio da sua experiência. Com o ingresso de novos profissionais, espera-se que o cuidado oferecido as parturientes considerem as suas dimensões fisiológicas, psicológicas, espirituais e o meio a qual ela está inserida, respeitando a sua totalidade (Cabral, Martins \& Arrais, 2012).

Mediante isso, utilizou-se a Gestalt-terapia como linha teórica de embasamento, por apresentar-se como uma abordagem Humanista, fenomenológica e Existencial, e por possuir uma visão holística de homem e de mundo, que se preocupa com a valorização do humano, compreendendo o homem na sua totalidade, com potencial criativo, com tendências à reestruturação e ao equilíbrio (Perls, Hefferline \& Goodman, 1997).

O interesse por esse estudo surgiu após assistir ao filme "O renascimento do parto", que nos foi ofer- tado no primeiro encontro do projeto de extensão do Centro Universitário Jorge Amado, denominado Laboratório de Gestalt-terapia, que propõe numa das linhas de pesquisa, estudar sobre a gestação e parto. O filme retrata a grave realidade obstétrica no Brasil e as evidências científicas que descredibilizam argumentos utilizados para os números de intervenções cirúrgicas realizadas no Brasil.

Considera-se de suma importância a exploração dessa temática no contexto acadêmico, não só na graduação de psicologia, mas abrindo essa reflexão em todas as graduações de saúde. Pois,com o surgimento das novas evidências e dos novos programas de humanização, torna-se indispensável que os profissionais da área de saúde sejam preparados e atualizados, para agirem com compreensão e empatia, quando estiverem diante do fenômeno do parto, dando o suporte necessário para cada mãe e família (Diniz, 2005).

Dessa forma, esse artigo pretende descrever o parto enquanto possibilidade de ampliação da consciência dos sujeitos envolvidos na experiência e responder como a institucionalização e masculinização da assistência ao parto afasta as gestantes do protagonismo da sua experiência. Para tanto,será analisada a trajetória dos diferentes modelos de assistência ao parto. Buscou-se também indicar as possibilidades de assistência humanizada no Brasil e discutir o papel do psicólogo, em especial o Gestalt-terapeuta, na gestação, parto e puerpério.

Esta é uma pesquisa bibliográfica de cunho qualitativo, construída por meio de um levantamento científico, datado entre 2001 a 2016, utilizando documentário, jornal, cartilhas do Ministério da Saúde, livros e artigos científicos encontrados na base de dados do SCIELO, EBSCO, PEPSIC, Google Acadêmico e biblioteca virtual de Saúde, utilizando os seguintes descritores: Parto humanizado, Trajetória de assistência ao parto, parto natural, Psicologia e parto, Psicologia e gestação.Segundo Boccato (2006) a pesquisa bibliográfica:

[...] busca a resolução de um problema (hipótese) por meio de referenciais teóricos publicados, analisando e discutindo as várias contribuições científicas. Esse tipo de pesquisa trará subsídios para o conhecimento sobre o que foi pesquisado, como e sob que enfoque e/ou perspectiva foi tratado o assunto apresentado na literatura científica. Para tanto, é de suma importância que o pesquisador realize um planejamento sistemático do processo de pesquisa, compreendendo desde a definição temática, passando pela construção lógica do trabalho até a decisão da sua forma de comunicação e divulgação. (p. 266)

Este artigo está dividido em seis seções. Nas três primeiras seções, após a introdução, foram 
apresentadas os mais relevantes aspectos de transformação da assistência ao parto e os movimentos atuais relativos a esse tema, no contexto brasileiro. A sessão quatro relata sobre a inserção do psicólogo no acompanhamento pré-natal e as possibilidades do Gestalt-terapeuta nessa conjuntura, ao passo que, a sessão cinco aborda o parto como uma experiência de dimensões fisiológicas, psicológicas e ambientais, sendo compreendido nesse trabalho como uma Gestalt, por possuir essa visão de totalidade. Na sessão seis essa pesquisa é finalizada, posto que, é nessa que são expostas as considerações finais.

\section{Trajetória do modelo de assistência ao parto brasileiro: masculinização e institucionalização}

Até o começo do século XIX, médicos raramente eram solicitados em partos, apresentando-se apenas em casos graves, que colocasse em risco a vida da mãe ou do bebê. Até então, o cuidado com a gestante e parto, era de domínio das mulheres (Rohden, 2012). Os partos em sua maioria eram realizados nos domicílios das parturientes, com a presença da família e apoio de parteiras de confiança, que descobriram a sua prática, através do conhecimento repassado de geração em geração, da intuição e da sua própria experiência (Progianti, 2001). Conforme Del Priore (1995):

Esta coisa de mulher em que se constituía dar à luz requeria ritos e saberes próprios, em que os homens só interfeririam em casos de emergência e, sobretudo, nos centros urbanos. A presença masculina no parto era desconfortável, nem sempre bem vinda, porque, além dos médicos mostrarem-se em seus relatos absolutamente insensíveis à dor das parturientes, as mulheres pareciam também atingidas pelo tabu de mostrar seus genitais, preferindo, por razões psicológicas e humanitárias, a companhia das parteiras. (p. 263)

Nos séculos XVII e XVIII, a medicina hegemonicamente masculina, passou a se interessar por assuntos obstétricos, tal fenômeno se iniciou na Europa, desdobrando-se para o Brasil no século XIX, com a criação das escolas de Medicina e Cirurgia nos estados do Rio de Janeiro e da Bahia (Rohden, 2012).

$\mathrm{O}$ afastamento e a deslegitimação das parteiras ocorreu gradualmente. Em 1832, cursos para parteiras foram ministrados, com o objetivo de ensiná-las a prática de assistência ao parto, de acordo com a ciência médica. A certificação recebida por essas mulheres, após a finalização do curso, garantia maior status social e confiança da população (Rohden, 2012).

Décadas depois, com a crescente especialização em assistência obstetrícia por médicos, foi demarcado o real afastamento das parteiras, tornando assim, o parto uma prática particularmente médica. Corrêa(2001) critica:

A deslegitimação das parteiras e a desapropriação do conhecimento das mulheres em geral sobre aqueles fenômenos da reprodução faz parte de um processo mais amplo de racionalização das condutas cotidianas, tal processo tem nos médicos e educadores como agentes primordiais e as regras de puericultura como veículo principal. (p. 43)

Já no século XX, o parto passou a ser, predominantemente, realizado em hospitais, médicos então, passaram a fazer partos e transformaram o momento de parir em um procedimento institucionalizado, agendado e mecanizado, dando maior controle a equipe e supostamente garantindo a mulher segurança e rapidez. Conforme Odent (2007):

Mas houve um passo novo na metade do século $\mathrm{XX}$, que foi a masculinização da cena do parto. Além de cada vez mais médicos se especializaram em obstetrícia, subitamente, na década de 1970, havia uma nova doutrina do pai participando do processo de parto. Também foi o momento em que as máquinas eletrônicas e a alta tecnologia foram introduzidas na cena do parto. Ou seja, o ambiente do nascimento se tornou altamente masculino. (p.17)

Mediante a incorporação da assistência obstétrica pela medicina, surge uma nova forma de nascer, institucionalizada e masculinizada. O nascimento passa a ser entendido como uma experiência perigosa e dolorosa. Ehrenreich eEnglish (1973) expõem o caráter patologizante que a medicina intervém nas manifestações inerentemente femininas, como a menstruação, gravidez, parto e menopausa, tratando-as como doenças crônicas, passíveis de intervenções cirúrgicas. Lima (1997, p.26) confirma "Dentro da orientação do modelo biomédico, onde a assistência é caracterizada por partos hospitalares em que a mulher permanece deitada todo o tempo, assistida exclusivamente pela equipe médica e submetida a ações medicalizadoras, distante da família, submissa, controlável”.

Inicia-se então, a medicalização do corpo feminino e seus fenômenos, e o distanciamento das mulheres, parteiras e parturientes, da experiência do nascimento. Segundo Foucault (2008), essas ações medicalizadoras tem como objetivo o controle social, que tem ínicio com ocontrole da reprodução e a sexualidade. Servindo também, para prolongar a idéia da incompletude feminina e o afastamento dos sujeitos na tomada de decisões referentes ao seu corpo e bem-estar (Corrêa, 2001).

Como se percebe, a mudança paradigmática que transfere os partos realizados em casa para as 
instituições hospitalares tem justificativa multifatorial. Além do interesse biopolítico do capitalismo, que objetiva executar controle social mediante a normatização dos fenômenos e domínio sobre os corpos, há também o retorno lucrativo que os hospitais obtêm com o nascimento institucionalizado, que passam a ser esquematizado, manipulável, rápido e muitas vezes previsível.

Outra causa é visão patologizante, que o parto gradualmente foi recebendo, e falácias disseminadas na nossa sociedade sobre a falta de capacidade da mulher moderna de parir, vulnerabilizam as gestantes estimulando-as a escolher ou aceitar métodos intervencionistas, como demonstra a OMS (2001):

A mulher parturiente está cada vez mais distante da condição de protagonista da cena do parto. Totalmente insegura, submete-se a todas as ordens e orientações, sem entender como combinar o poder contido nas atitudes e palavras que ouve e percebe, com o fato inexorável de que é ela quem está com dor e quem vai parir. (p.18)

Dessa forma, pode-se observar, a massiva e incessante busca por conformidade e praticidade, em qualquer que seja o fenômeno, incluindo o corpo feminino e o parto, afastando os sujeitos de vivenciar integralmente a sua experiência.

Reich (1983) observa que o papel da medicina é de auxiliar no desenvolvimento das funções naturais do corpo, mas ao invés disso, por meio de suas práticas e procedimentos tecnológicos ela distancia os sujeitos da tomada de decisão "Nós devemos promover e não impedir as funções naturais do corpo [...] Somente intervir quando a própria natureza não podia superar as lesões" (p. 139).

Portanto, o modelo institucionalizado e masculinizado sugestiona as parturientes e as enfraquece, e desempoderadas, passam a ignorar aos seus sentimentos, desejos e emoções para responder adequadamente as expectativas sociais e as inclinações culturais, que determinam padrões rígidos para o nascimento, distanciando-as assim, da sua natureza e do controle do seu próprio corpo.

\section{Trajetória do modelo de assistência ao parto: tecnocracia $\mathrm{x}$ humanização}

No século XIX, o modelo tecnocrático, também conhecido como biomédico, vem incorporar a assistência ao parto, com a institucionalização do nascimento. Trazendo importantes avanços tecnológicos e novos conhecimentos, ele passa a ser predominantemente utilizado em nossa sociedade.

Uma das características implícitas do modelo biomédico na assistência ao parto, é a separação, separação entre mente e corpo, separação entre a parturiente e a sua família, e a tão problemática, separação entre mãe e filho, logo após o nascimento. São características também, a indução, o uso agressivo de tecnologias e a padronização do cuidado. A mulher mantêm-se internada, muitas vezes, desacompanhada, dispondo de poucas informações e pouca autonomia em relação ao seu corpo e o trabalho de parto, onde passa a sofrer intervenções, na maioria das vezes desnecessárias (Ministério da Saúde, 2002).

As tecnologias intervencionistas inseridas na assistência ao nascimento, quando utilizadas por razões medicamente necessárias, apresentam-se como possibilidades de salvar a vida de mães e bebês, porém, taxas superiores a 10\% de cesáreas não estão associadas com redução de mortalidade materna e neonatal, pelo contrário, em decorrência dos procedimentos rígidos adotados pela tecnocracia, a realização indiscriminada de cesarianas, aumentam a probabilidade de complicações materno-infantil (OMS, 2015).

Entende-se aqui como práticas intervencionistas, a inserção de tecnologias que interferem na fisiologia do nascimento. Conforme Vargens, Silva, Reis e Progianti (2013) práticas intervencionistas são:

As práticas amplamente utilizadas no modelo medicalizado, como a administração endovenosa de ocitocina durante o trabalho de parto, a realização indiscriminada da amniotomia e da episiotomia e a restrição ao leito no trabalho de parto, foram consideradas intervenções na fisiologia do parto. (p.1)

A força do modelo biomédico justifica-se por atender aos interesses dos médicos, que com as cesarianas agendadas, possuem um melhor incentivo financeiro, mais previsibilidade, diminuição de riscos e maior controle de horários, se comparados com os partos normais, que podem durar muitas horas. Constata-se que ao iniciar o pré-natal, por não possuir conhecimento suficiente ou por se sentirem inseguras, uma parte das gestantes delegam aos médicos a tomada de decisão sobre o percurso até o nascimento, confiando assim, nas suas condutas. $\mathrm{O}$ sugestionamento daqueles que se beneficiam com os partos cirúrgicos, geram comumente a indução de demanda, que segundo Cutler e Zeckhauser (2000) acontece quando com base em interesses próprios, os médicos manipulam o paciente para aceitar o procedimento ou tratamento que gere diretamente ou indiretamente mais benefícios para ele.

Outro componente que influência na potência da tecnocracia é a decisão da parturiente, que em razão de uma construção sócio-histórica, sentem-se beneficiadas com a cesárea, muitas vezes, em decorrência da visão naturalizada da segurança do ambiente hospitalar, o medo da dor, questões relacionadas a estética e dos mitos relacionados ao parto natural (Hopkins, 2000).

Em vista disso, surgem novos movimentos sociais e políticas públicas, buscandofazer frente a 
violenta realidade obstetrícia atual, que pauta a sua atuação na cristalização de mitos construídos historicamente,entre eles o que a mulher é incapaz de parir, que o parto é perigoso para criança ou que a vagina após o nascimento do bebê ficará larga, justificando assim, suas práticas e procedimentos coisificadores e normatizadores, desconsiderando as especificidades do fenômeno como ele se apresenta. Dentre elas podemos citar: a medicina baseada em evidências e humanização do pré-natal e nascimento.

Nesse sentido, Melania Amorim (2012), obstetra e militante em favor do parto natural, apoiada na medicina baseada em evidências, questiona as práticas obstetrícias naturalizadas:

A Medicina Baseada em Evidências (MBE) [...]
entrou em minha vida por volta de 1994, quan-
do eu era ainda uma jovem obstetra formada
dentro do modelo tecnocrático. [...] Quando co-
mecei a pesquisar seriamente sobre esses pro-
cedimentos, fiquei espantada ao constatar que
não havia nenhuma evidência científica sólida
demostrando sua necessidade e efetividade e,
ao contrário, já existiam evidências demostran-
do os seus efeitos deletérios para o binômio
mãe-bebê. (p. 19)

Nota-se que o uso de intervenções cirúrgicas desnecessárias trazem repercussões negativas tanto para a saúde da mãe e do bebê, quanto para o governo que tem um aumento significativo do custo geral, devido a utilização de mais materiais e procedimentos, prolongamento das internações e números de profissionais envolvidos no cuidado na hora do nascimento (Hopkins, 2000).

A humanização aparece nessa perspectiva com o objetivo de estimular a participação ativa dos processos vivenciados, devolvendo aos sujeitos a autonomia e a dignidade, proporcionando a alteração do ambiente e dos autores envolvidos, bem como, mudanças nas condutas realizadas. Nesse modelo a parturiente passa a não ser mais considerada como um objeto, no qual se fazem procedimentos de extração do bebê, mas uma pessoa de quem se espera um papel ativo, capaz de gestar e de parir (Diniz, 2001).

Não obstante, o modelo humanista propõe a valorização da dimensão subjetiva e social, na prática de atenção ao cuidado da população, refletindo sobre as antigas práticas, sugere um novo modo de relacionamento entre cuidador e paciente, pautada na horizontalidade, colocando-se diante ao outro empaticamente, de modo a desenvolver um cuidado que recria a sua forma, o seu funcionamento e as suas interações mediante ao encontro (Ministério da Saúde, 2002).

A humanização abre espaço para inserção do psicólogo no acompanhamento perinatal, o que contribui para o processo de passagem das gestantes da heteronomia para a autonomia. Com a construção da autonomia vai-se preenchendo o espaço antes dominado pela dependência. Assim sendo, o psicólogo por intermédiode técnicas psicológicas, manejos e a vinculação, propiciará a instrumentalização do sujeito possibilitando-o tomar suas próprias decisões, diante das imposições sociais. Contudo, Freire (1997) aborda que a autonomia não pode ser concedida, sendo assim, desenvolvida mediante um processo e afirma que "ninguém é sujeito da autonomia de ninguém. Por outro lado, ninguém amadurece de repente. A gente vai amadurecendo todo dia, ou não. Autonomia é processo, é vir a ser" (p.120).

A relação da tecnocracia e humanização, assemelha-se a um dos conceitos mais famosos de Buber (1977) que é a relação Eu-Tu, Eu-Isso. Uma relação saudável abarcaria tanto a atitude Eu-tu, quanto a atitude Eu-Isso, integrando as polaridades. Porém, o que percebe-se é que no modelo tecnocrático há uma prevalência do modelo Eu-isso, em que fenômenos humanos passam a ser vistos predominantemente de maneira objetiva, a partir de um propósito, acarretando a reificação do outro. Enquanto no modelo de humanização existe um equilíbrio das polaridades, dessa forma, a singularidade do sujeito a quem se está defronte é respeitada e acolhida, conferindo a essa relação reciprocidade.

Na assistência ao parto, essa dinâmica tecnocráticatorna-se evidente, já que o modelo hegemônico atual de assistência obstétrica é exclusivamente pautado na relação Eu-isso,sendovista como uma prática de coisificação do ser humano, a parturiente é considerada como um objeto e o nascimento um objetivo, configurando-se como um processo de desumanização. Vale ressaltar, que o modelo de humanização não pretende excluir o masculino da cena do parto, mas devolver o protagonismo as mulheres nesse processo, que conscientes das suas possibilidades possam parir da maneira mais confortável, segura e acolhedora possível. É a partir de um cuidado humanizado e emancipador, que se pode estimular a capacidade de autorregular-se e atualizar a si e as suas fronteiras no processo experienciado, rompendo com antigas convicções e abrindo-se para o devir, ou seja, o vir a ser.

\section{Panorama de assistência perinatal no contexto brasileiro}

Mesmo depois de duas décadas da instituição do Programa de Assistência integral à saúde da mulher (PAISM), existem no Brasil, grandes desafios a serem enfrentados. No final dos anos 90, a saúde da mulher se torna prioridade para o MS, repercutindo em três principais objetivos: melhorar a saúde reprodutiva, reduzir a mortalidade por causas evitáveis e combater a violência contra a mulher (Serruya, Lago\&Cecatti, 2004).

Nesse período, a busca por humanização na saúde havia ganhado destaque, surgindo assim, programas que incentivavam um atendimento digno e 
acolhedor aos pacientes e o uso consciente de tecnologias no cuidado, não só na instituição hospitalar, mas em toda rede do SUS. O MS (2002) define a humanização, dividindo-a em dois aspectos:

O primeiro diz respeito à convicção de que é dever das unidades de saúde receber com dignidade a mulher, seus familiares e o recém-nascido. Isto requer atitude ética e solidária por parte dos profissionais de saúde, organização da instituição de modo a criar um ambiente acolhedor e adotar condutas hospitalares que rompam com o tradicional isolamento imposto à mulher. $\mathrm{O}$ segundo refere-se à adoção de medidas e procedimentos sabidamente benéficos para o acompanhamento do parto e do nascimento, evitando práticas intervencionistas desnecessárias que, embora tradicionalmente realizadas, não beneficiam a mulher nem o recém-nascido e que, com frequência, acarretam maiores riscos para ambos. (pp. 5-6)

Com sentido de prestar um cuidado pautado na humanização e minimizar a morbidade e mortalidade materno-infantil, foi elaborado pela Área Técnica de Saúde da Mulher junto à Secretaria de Assistência à Saúde e Secretaria Executiva, um projeto dividido em três etapas. Instituída pela portaria MS/GM 2.816, de 29 de maio de 1998, a primeira, elevou a remuneração ao parto normal e demarcou os honorários de cesáreas por instituição hospitalar. A segunda etapa, instituído pela Portaria MS/GM 3.016, de 19 de junho de 1998, foi instaurado o Programa de Apoio à Implantação de Sistema Estadual de Referência Hospitalar para a gestação de alto risco. Já a terceira, teve por finalidade de melhorar a qualidade de assistência perinatal mulher (Serruyaet al, 2004).

Em decorrência das necessidades de cuidados mais específicos na gestação, parto, puerpério e nascimento, bem como, diminuir as taxas de cesarianas no Brasil,é instituído em 2000 pelo MS através da Portaria/GM n.o 569, de 1/6/2000, o Programa de Humanização no Pré-natal e Nascimento(PHPN), que por via de incentivos financeiros, busca assegurar uma assistência ao pré-natal, parto e puerpério humanizada e de qualidade, tomando como pressuposto que a humanização nesse período, é condição essencial para um acompanhamento apropriado do parto e do puerpério.

Apesar dos esforços do PHPN, as taxas de mortalidade materno e neonatal continuam exorbitantes e o uso de tecnologias intervencionistas desnecessárias no parto permanecem elevadas. Visando o enfrentamento dessa realidade e da violência obstetrícia, foi desenvolvido em 2011, também pelo Ministério da Saúde, o programa Rede Cegonha (portaria MS/GM n ${ }^{0} 1.459 / 2011$ ), que pretende oferecer um novo modelo de cuidado à saúde da mãe e criança, com idades de zero a vinte e quatro meses e assegurar às parturientes, uma rede de cuidados que permita o planejamento reprodutivo e o cuidado humanizado e seguro durante toda a gestação e parto (Brasil, 2011).

Em 2005, em decorrência dos movimentos de humanização, é instituída a Lei número 11.108, que garante a parturiente o direito ser acompanhada no momento do parto, por alguém da sua escolha. Segundo Teles, Pitombeira, Oliveira, Freitas, Moura e Damasceno (2010), a presença de um acompanhante, propicia à mulher sensação de segurança e satisfação, possibilitando menos intervenções no parto.

Além do companheiro ou familiares, a parturiente também pode ser acompanhada por uma doula. A doula é uma mulher que presta cuidados e suporte físico e emocional à mãe e os demais acompanhantes, durante o trabalho de parto, estimulando o maior conforto possível nesse processo, através de massagens, técnicas de respiração, apoio e esclarecimento de dúvidas relacionadas a evolução do parto (Santos \&Nunes, 2009).

Contudo, evidencia-se que tais programas encontraram uma série de desafios para sua implantação. Entre eles, podemos citar: dificuldades institucionais, financeiras e de estruturas físicas, bem como, no que diz respeito ao capital humano, pois a humanização propõe uma série de inovações na forma de assistir aos pacientes, o que, muitas vezes, é divergente à práticas cotidianas, construídas historicamente e cristalizadas pelos profissionais, o que gera recusa e baixa implementação das ações (Boareto, 2001).

\section{A inserção do psicólogo gestalt-tera- peuta no acompanhamento em torno ao nascimento}

O acompanhamento perinatal pode ser definido como uma série de práticas que assistem a saúde da gestante e do bebê, durante a gravidez, parto e puerpério. Historicamente tal cuidado era realizado por médicos e enfermeiras. No entanto, nos últimos vinte anos, a assistência ao pré-natal, tem passado por constantes modificações, no sentido de melhorar a qualidade do serviço oferecido a população e minimizar a mortalidade materno infantil.

Com o estabelecimento dos programas atuais, surgiram novas práticas de assistência, que descentralizam o poder médico e o foco exclusivo no procedimento cirúrgico, introduzindo novos atores, possibilitando um cuidado integral e multiprofissional. Tais mudanças, viabilizaram a ampliação do cuidado em torno ao nascimento. Originando o pré-natal psicológico, emergindo com caráter complementar ao pré-natal tradicional, com base noprograma de Humanização no Pré-natal e Nascimento, instituído pelo Ministério da saúde (Tostes, 2012).

A importância do pré-natal psicológico se dá, visto que, a gestação possui uma magnitude organísmica incontestável, que pode ser influenciada por 
diversos fatores. O processo iniciado na gestação e estendido ao puerpério expõe a mulher a importantes questões existenciais, como a angústia, o amor e a morte. E é comum que nesse período, a gestante esteja mais fragilizada, visto que, além da conjuntura comum à gravidez, existe uma série de influências socioculturais que deslegitimam o feminino e propõem uma maneira normatizada de parir e de ser mãe. Nesse sentido o apoio psicológico possibilita a prevenção e diagnóstico precoce de possíveis psicopatologias do ciclo gravídico-puerperal, além de, utilizandotécnicas psicológicas, fortalecer e devolver o poder em relação ao que ocorre com o seu corpo (Arrais, 2005).

Essa nova conjuntura de fazer psicológico, fundamentada na atual concepção de saúde, que prevê influências de múltiplas dimensões e não apenas ausência de doenças, demarca para a psicologia, um outro campo de atuação. Nele, a prática não modela-se apenas no sujeito isoladamente, mas na compreensão do homem como um ser biopsicossocial-espiritual, que integra e é integrado em um campo. Tal perspectiva é comumente denominada como clinica ampliada, pois não se restringe à tradicional psicoterapia individual, mas "Integra a estrutura psíquica e o pertencimento social, abarcando a complexidade das relações que definem as posições dos sujeitos no mundo" (Brito, 2015, p. 166).

A visão holística de homem, solicitada no acompanhamento perinatal humanizado, é perfeitamente congruente com a perspectiva gestáltica, pois essa compreende que o homem e o meio, permutado pelo contato, correspondem a uma totalidade, uma unidade que não pode ser dividida ou compreendida isoladamente. Em termos correspondentes a gestação, a mulher em seus aspectos psicológicos, fisiológicos, o ambiente e os fenômenosque emergem, são manifestações de um todo indivisível (Brito, 2015).

Sendo a Gestalt-terapia, uma abordagem psicoterapêutica, que surgiu com o descontentamento de Frederick Perls com os métodos existentes em sua época. Elaborando então, junto à Laura Perls, Goodman e Hefferline, um movimento de busca de outras fontes que viessem a responder os fenômenos humanos. Com base em algumas influências intelectuais, é criada a Gestalt-terapia, que mais do que uma perspectiva teórica, é uma forma diferente de ver o mundo.

Gestalt-terapia, embora formalmente apresentada como um tipo de psicoterapia é baseada em princípios que são considerados como uma forma saudável de vida. Em outras palavras, é primeiro uma filosofia de vida, uma forma de ser, e com base nisto, há maneiras de aplicar este conhecimento de forma que outras pessoas possam beneficiar-se dele. (Perls, como citado em Stevens, 1975, p. 14)
Nesse contexto, em que a gestante é dissociada da experiência atual, tornando-se coadjuvante no processo, a Gestalt-terapia deve se debruçar em estimular a awareness, que segundo Ginger (1995, p. 254), é a "tomada de consciência global no momento presente, atenção ao conjunto de percepção pessoal, corporal e emocional, interior e ambiental, consciência de si e consciência perceptiva".

Devendo ainda, auxiliar os sujeitos na busca de si mesmo, desenvolvendo o potencial humano, estimulando uma existência mais autêntica, focada no aqui-agora e um contato saudável, em que o indivíduo seja capaz de assimilar novidades nutritivas e afastar-se do que é nocivo, podendo assim se desenvolver e se apropriar das próprias escolhas, tornando-se protagonista da sua história (Brito,2015).

O pré-natal psicológico realizado pelo psicólogo Gestalt-terapeuta, dispõe de recursos importantes e pode ser realizado tanto individualmente, quanto em grupo. Em ambos os casos, sugere-se que o psicólogo se abstenha de juízos de valor e ofereça uma escuta sensível e de qualidade, promovendo suporte às questões que se impõem no campo organismo-meio, proporcionando um local seguro para expressão de sentimentos, pensamentos, medos e fantasias, que emergem como figura durante o pré-natal psicológico. Sendo os medos mais comuns no período gestacional, a perda do bebê, filho com deficiência, questões ligadas à sexualidade e tipo de parto, o acolhimento de tais receios, possibilita minimizar ansiedades, promover a tomada de consciência e a ampliação do repertório de enfrentamento.

Dentre as temáticas, a serem abordadas no pré-natal psicológico, questões acerca da idealização tanto da maternidade, quanto desse bebê idealizado, devem ser trabalhadas, auxiliando assim, a elaboração do luto frente à inconcretude do ideal no real, e possibilitando a compreensão do tornar-se mãe como uma construção subjetiva e intersubjetiva, para além, do modelo de maternidade estabelecido socialmente. Estimulando, a participação da rede de apoio, nos processos da gestação, nascimento e puerpério, que podem ser configurados de diferentes formas(Arrais, Mourão \& Fragalle, 2014).

À vista disso, demonstra-se que o Gestalt-terapeuta, pode auxiliar no empoderamento dessa gestante, facilitando a tomada de consciência e a vivência ativa da experiência do parto, estimulando-a se concentrar nas manifestações presentes no aqui-agora, se abrindo criativamente para a novidade e o desconhecido que afloram durante o processo gestacional e puérperal, estando presente de forma genuína e ativa na experiência.

\section{0 parto vivido: uma perspectiva ges- táltica}

Pensar o parto por uma perspectiva gestáltica é ter como premissa básica, que ele não pode ser entendido pelos seus elementos individuais, tais 
como aspectos fisiológicos, psicológicos ou ambientais, e sim pela totalidade dos seus fenômenos. O organismo passa a ser compreendido como um agrupamento organizado, com leis que autorregulam o funcionamento, em que nem uma das suas partes, tem supremacia sobre outra. Dessa forma, não há dicotomia entre mente e corpo, entendendo-os como um organismo em um campo interacional e interdependente.

Não há uma única função, de animal algum, que se complete sem objetos e ambiente, quer se pense em funções vegetativas como alimentação e sexualidade, quer em funções perceptivas, motoras, sentimento ou raciocínio [...] E lembremo-nos de que qualquer que seja a maneira pela qual teorizamos sobre impulsos, instintos e etc., estamos nos referindo sempre a esse campo interacional e não a um animal isolado. (Perls et al, 1997, pp. 42-43)

O parto compõe uma unidade em funcionamento, em que atividades mentais e físicas são partes de um todo, dessa forma, reconhecemos o parto como uma Gestalt. Existindouma série de manifestações organísmicas,que configuram o processo de autorregulação no trabalho de parto, tais como: contrações uterinas, liberação de hormônios facilitadores do parto, busca por privacidade e por posições e posturas mais confortáveise que ocorrem na fronteira de contato, o "lócus" em que acontece a interação entre meio e organismo (Perls et al, 1997).

Para que o parto aconteça de maneira natural, o campo no qual a gestante irá parir deve ser favorável a fisiologia do parto e a gestante capaz de se adaptar às demandas que surgem no processo se ajustando criativamente. Como campo, entende-se a totalidade dos fatos coexistentes, concebidos em termos de mútua interdependência. Nesse contexto, para que sejam liberados os hormônios que facilitam o trabalho de parto, como a ocitocina, alguns fatores devem ser respeitados, devendo ser garantido à parturiente, privacidade, penumbra e pouco barulho. Pois se a parturiente não se sentir segura, o organismo se autorregulará de modo a liberar adrenalina, desencadeando a cessação do trabalho de parto, evidenciado que as forças subjacentes que compõe o campo, influenciam o comportamento no aqui-agora (Ribeiro, 2006).

Principalmente durante o parto natural, esse sujeito no campo, libera um coquetel de hormônios, intitulado por Michel Odent (2002) como "hormônios do amor”, tais hormônios são responsáveis pela contração uterina, contração das glândulas mamárias e a ejeção do leite, por amenizar o estresse e o cansaço sentido pela mãe no pós-natal, além de facilitador do vínculo e dependência entre mãe e filho.É importante esclarecer ainda, que o cérebro humano só reconhece hormônios produzidos pelo próprio corpo, demonstrando a necessidade de valorizar essa experiência de adaptação e restruturação do organismo. Sendo produzidos dessa forma, exclusivamente no trabalho de parto.

A adrenalina que precocemente liberada poderia inibir o trabalho de parto, no nascimento possui papel de facilitador do cuidado, pois ajudará a parturiente a ficar atenta após o nascimento e aliada a grande liberação de ocitocina, facilita a formação do vínculo afetivo. Conforme Peterson (1996), a vivência ativa do parto interfere diretamente na autovalorização, autoimagem e na receptividade afetiva e emocional da mulher para com seu filho, logo após o nascimento.

Além disso, o trabalho de parto é em si, um processo de transição para a maternidade, solicitando da mulher, capacidade de ajustamento criativo continuo, ou seja, a capacidade de adaptar-se as circunstâncias a medida que irão surgindo. Nesse sentido, a vivência da dor durante as contrações no processo de parto e a alteração no estado de consciência que comumente acontece no parto natural, quando a parturiente toma posse do fenômeno, vivenciando a experiência e suspendendo a racionalização para que o trabalho de parto aconteça de maneira singular e subjetiva é uma preparação ritualística do corpo, dando espaço para a construção de outra subjetividade, do ser mulher para o tornar-se mãe. Segundo Carneiro (2013):

Nesses momentos, uma das metáforas mais usadas "escalada da montanha”. O parto é assim pensado, é preciso subir, esforçar-se para chegar ao topo e apreciar a vista. "Subir de helicóptero também leva ao topo, mas perde-se a experiência, o caminho e a passagem” (notas de campo, idem). O helicóptero seria, então, a analgesia ou a cesárea e, consequentemente, a perda do caminho seria a perda das sensações do trabalho de parto. "Escalar a montanha" aparece similarmente como a importância de “manter o ritmo", que, no parto, seria o da respiração, do desejo de fazer força e o do cansaço diante de horas e horas de trabalho (p. 2373).

O estar presente nessa experiência, possibilita a vivência dessas etapas subjetivas, que possibilitam conferir sentido e configurar a maternagem, tornando-se importante no estabelecimento dos laços afetivos com o bebê.

Segundo Frank e Pelloso (2013), o parto domiciliar planejado favorece a autonomia da parturiente, já que nesse espaço, a mulher sente-se segura em fazer escolhas, tendo a oportunidade de se locomover livremente, resgatar o controle do seu corpo e vivenciar a experiência do parto com menos inibições, tornando-se sujeito ativo no processo.

Mas, apesar das especificidades e o potencial do parto natural humanizado, o parto nem sempre 
termina de maneira ideal e nesse sentido, é necessário que a parturiente esteja em contato consciente com o organismo-campo e ajuste-se criativamente, ou seja, crie de maneira dinâmica, meios para a satisfação das necessidades mais prioritárias, afim de, restabelecer o equilíbrio no campo em que ele faz parte, mantendo-se como protagonista da experiência (Ribeiro, 2006).

Por esse ângulo, podemos perceber, que mesmo que o parto não aconteça de maneira natural, há a possibilidade de torná-lo mais humanizado, para isso, a subjetividade da mulher e suas escolhas devem ser acolhidas e respeitadas, e alguns cuidados sejam tomados, a fim de considerar as dimensões fisiológicas, psicológicas e ambientais da parturiente.

Para que a Gestalt do parto seja fechada, a parturiente deve ser capaz de manipular a si própria e o seu meio, gerando um livre fluxo de formação e fechamento de necessidades (gestaltens), promovendo assim, uma interação do organismo com o meio. Como demonstra a ilustração abaixo:

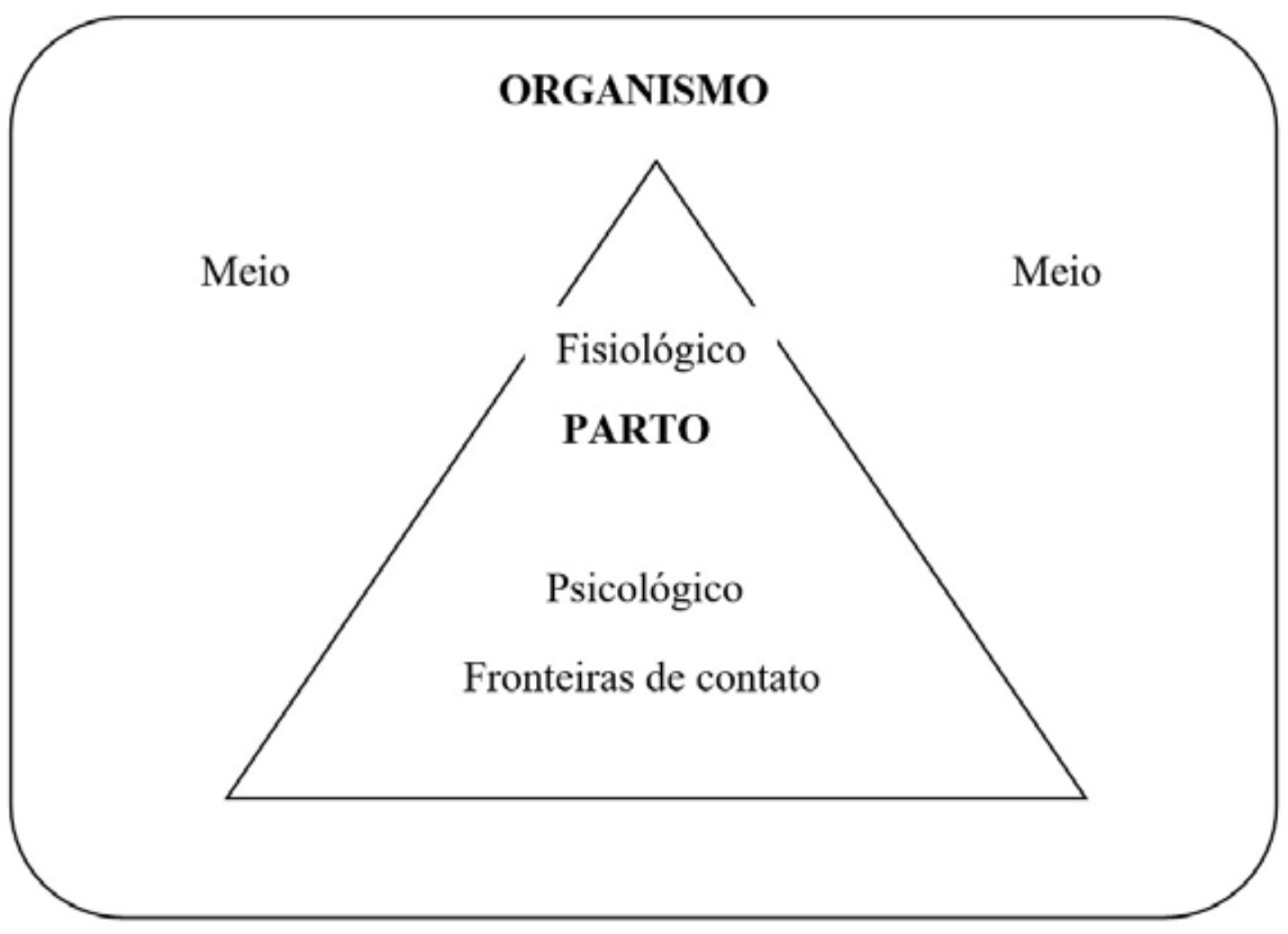

Fígura 1- Gestalt do parto

(Fonte: Produzido pelo o autor)

\section{Considerações finais}

A presente pesquisa teve como principal objetivo descrever o parto enquanto possibilidade de ampliação da consciência dos sujeitos envolvidos na experiencia. Para isso, decidiu-se iniciar apresentando a trajetória de assistência ao parto, que evidenciou que ao passar dos anos, com o fortalecimento do modelo biomédico, as parturientes tem sido constantemente afastadas da experiência do parir e vistas como um objeto submisso e sem voz nesse processo. Constatou-se que a partir da influência do capitalismo e o controle dos corpos, houve a reificação dos fenômenos femininos ea relação médico-paciente, passou a ter caráter predominantemente EU-ISSO.

Em vista disso, seguiu-se o artigo, explanando sobre as novas políticas e movimentos sociais no contexto brasileiro, que se opuseram ao modelo tecnocrático, junto com as novas evidências, com o sentido de humanizar o processo em torno do nas- cimento e diminuir a mortalidade materno-infantil. Sendo possível atestar que, a humanização e valorização da subjetividade do sujeito a quem se estar defronte é fundamental para uma experiência saudável e ativa do parto, pois com ela a parturiente pode passar da sujeição da autoridade médica para autonomia.

O psicólogo se insere no acompanhamento pré-natal, apoiado pelo programa de humanização de pré-natal e nascimento, com base na necessidade de um espaço seguro para expressão de sentimentos vivenciados na gestação, objetivando estimular o empoderamento e o crescimento da gestante. Demonstrando, que a visão gestáltica de homem e mundo torna-se um recurso importante para que possamos refletir acerca do fenômeno da gestação, parto e puerpério, visto que, possibilita entender a gestante, seus fenômenos e o meio do qual ela faz parte, com base em uma totalidade, estimulando ainda, a toma- 
da de consciência e a vivência ativa da experiência do parto.

Foi possível perceber também, o parto como uma totalidade e sendo assim, parte de um campo. Ratificando que o ambiente no momento do parto deve ser favorável e seguro para que os seus fenômenos ocorram naturalmente. Além disso, tomando em contrapartida que o trabalho de parto, prepara a mãe e o bebê para sua nova etapa, podemos concluir que a cesariana dificulta a tomada de consciência, por afastar os seus protagonistas da experiência, já que ela deita-se grávida e levanta mãe.

As principais dificuldades encontradas para a construção desse estudo, ocorreram pela escassez de produções cientificas de psicologia e Gestalt-terapia à respeito do parto, nascimento e humanização nesses processos. Diante disso, sugerem-se novas pesquisas,especialmente sobre os efeitos do parto para o bebê a partir de um olhar da psicologia.

\section{Referências}

Amorim, M. (2012). Entre as orelhas: histórias de parto. Porto Alegre: Ideias a Granel.

Arrais, A. R.(2005). As configurações subjetivas da depressão pós-parto: para além da padronização patologizante (Tese de Doutorado). Universidade de Brasília, Brasília.

Arrais, A.R., Mourão, M. A. \&Fragalle, B. (2014). O pré-natal psicológico como programa de prevenção à depressão pós-parto. Saúde e Sociedade, 23(1), 251-264. Disponível em https:// dx.doi.org/10.1590/S0104-12902014000100020

Boareto, M. C. (2003) Avaliação da Política de $\mathrm{Hu}$ manização no Parto e Nascimento no Município do Rio de Janeiro(Dissertação de Mestrado). Escola Nacional de Saúde Pública, Fundação Oswaldo Cruz, Rio de Janeiro.

Boccato, V. R. C. (2006). Metodologia da pesquisa bibliográfica na área odontológica e o artigo científico como forma de comunicação. Rev. Odontol. Univ. Cidade São Paulo, 18 (3), 265-274.

Brito, M. A. Q. (2015). Gestalt-terapia na clinica ampliada. Em L. M. Frazão \& K. O. Fukumitsu (Orgs.), A clinica, a relação psicoterapêutica e o manejo em Gestalt-terapia (p.163-180). São Paulo: Summus.

Buber, M. (2001). Eu e Tu.(N. A. V. Zuben, Trad.). São Paulo: Centauro. (Originalmente publicado em 1923).

Cabral, D. S. R.; Martins, M. H. F.; Arrais, A.R.(2014). Grupo de pré-natal psicológico: avaliação de programa de intervenção junto a gestantes. Saúde Soc. São Paulo, 23(1), 251-264.
Carneiro, R. (2013). Daquilo que os médicos quase não falam: transe e êxtase na cena de parto. Experiências e percepções dissidentes de saúde e de bem-estar na contemporaneidade. Ciênc. saúde coletiva, 18(8), 2369-2378. Disponível em http:/www.scielo. br/scielo.php?script $=$ sci_arttext\&pid $=$ S141381232013000800021\&lng $=\overline{\text { en } \& \text { nrm }=\text { iso. }}$

Corrêa, M. V.(2001) Novas tecnologias reprodutivas: limites da biologia ou biologia sem limites?.Rio de Janeiro: Eduerj.

Cutler, D. \&Zeckhauser, R. (2000).The anatomy of health insurance.Em A. J. Culyer\& J. P. Newhouse (Orgs.), Handbook of health economics (p. 563-643). New York: Elsevier.

Del Priore, M. (1995) Ao sul do corpo: condição feminina, maternidades e mentalidades no Brasil colônia. Rio de Janeiro: José Olympio.

Dias, M.A.B. \& Domingues, R. M. S. M.(2005) Desafios na implantação de uma política de humanização da assistência hospitalar ao parto. Revista Ciênc. saúde coletiva, 10 (3), 699-705. Disponível em http://www.scielo.br/scielo.php?script=sci_arttext\&pi$\mathrm{d}=\mathrm{S} 1413-81232005000300026 \& \ln \mathrm{g}=$ en\&nrm $=$ iso.

Diniz, C.S.G. (2005). Humanização da assistência ao parto no Brasil: os muitos sentidos de um movimento. Revista Ciênc. Saúde Coletiva, 10 (3), 627-37.

Ehrenreich, B. \& English, D. (1973). Por su propio bien. 150 años de consejos de expertos a las mujeres. Madrid: Taurus.

Focault, M. (2008). Vigiar e punir: nascimento da prisão. (R. Ramalhete, Trad.).Petrópolis: Vozes. (Originalmente publicado em 1975).

Frank, T. C.\&Pelloso, S. M. (2013). A percepção dos profissionais sobre a assistência ao parto domiciliar planejado. Rev Gaúcha Enfermagem, 34(1), 22-29.

Freire, P. (1997). Pedagogia da Autonomia. São Paulo: Paz e Terra.

Ginger, S. \& Ginger, A. (1995). Gestalt: Uma Terapia do Contato.São Paulo: Summus.

Hopkins, K. (2000). Are Brazilian women really choosing to deliver by cesarean?.Social Science \& Medicine, 51(5), 725-740.

Lei $\mathrm{n}^{\mathrm{O}} 11.108$, de 7 de abril de 2005. (2005). Altera a Lei no 8.080, de 19 de setembro de 1990, para garantir às parturientes o direito à presença de acompanhante durante o trabalho de parto, parto e pós-parto imediato, no âmbito do Sistema Único de Saúde - SUS. Brasília. 2005. Recuperado em 30 de maio, 2016, de http://www. planalto.gov.br/ccivil/Leis/L9984.htm 
Lima, K. M. R. (1997). Maternidade Leila Diniz (1994 a 1996): Nascimento de um Novo Profissional de Saúde? (Dissertação de mestrado).Fundação Oswaldo Cruz, Rio de Janeiro.

Ministério da Saúde do Brasil. (1998). Assistência ao Parto Normal: um guia prático. Brasília.

Ministério da Saúde. (2001). Parto, aborto e puerpério - assistência humanizada à mulher ( $2^{\mathrm{a}} \mathrm{ed}$.). Brasília.

Ministério da Saúde do Brasil. (2002). Humanização do parto Humanização no Pré-natal e nascimento. Brasília.

Ministério da Saúde do Brasil (2002). Manual prático para implementação da Rede Cegonha. Brasília.

Odent, M.(2002). A cientificação do amor. Florianópolis: Saint Germain.

Odent, M. (2007). Parto e nascimento no mundo contemporâneo: Conferência de abertura do Seminário BH pelo Parto Normal [Resumo]. In Movimento BH pelo parto normal (org.), Resumos de comunicações científicas, Seminário $\mathrm{BH}$ pelo Parto Normal (p. 13-21). Belo Horizonte: PBH.

Organização Mundial da Saúde (2015) Declaração da OMS sobre Taxas de Cesáreas. Genebra.

Perls, F., Hefferline, R. \& Goodman, P. (1997). Gestalt-terapia. São Paulo: Summus.

Peterson, G. (1996). Childbirth: the ordinary miracle: effects of devaluation of childbirth on women's self-esteem and family relationships. Pre and Perinatal Psychology Journal, 11,101-109.

Portaria GM/MS n.2816, de 29 de maio de 1998. (1998). Determina que, no programa de digitação de autorizações de internação hospitalar SISAIH01, seja implantada crítica visando o pagamento de percentual máximo de cesarianas, em relação ao total de partos por hospital. Institui medidas para redução de cesáreas. Brasília. 1998. Recuperado em 10 abril, 2016, de http://sna.saude.gov.br/legisla/legisla/obst/GM P2816 98obst.doc

Portaria n. ${ }^{\circ}$ 3.016, de 19 de junho de 1998. (1998). Institui o Programa de Apoio à Implantação dos Sistemas Estaduais de Referência Hospitalar para Atendimento à Gestante de Alto Risco. Brasília. 1998. Recuperado em 10 abril, 2016, de http://sna.saude.gov.br/legisla/legisla/ obst/GM P3.016 98obst.doc
Portaria $n^{0} 569$, de 01 de junho de 2000. (2000). Institui o Programa de Humanização no Pré-natal e Nascimento, no âmbito do Sistema Único de Saúde. Brasília. 2000. Recuperado em 10 abril, 2016, de http://bvsms.saude.gov.br/bvs/saudelegis/gm/2000/prt0569_01_06_2000.html

Portaria $\mathrm{n}^{\mathrm{0}}$ 1.459, de 24 de junho de 2011. (2011). Institui, no âmbito do Sistema Único de Saúde - SUS - a Rede Cegonha. Brasília. 2011. Recuperado em 02 junho, 2016, de http:// bvsms.saude.gov.br/bvs/saudelegis/gm/2011/ prt1459_24_06_2011.html

Progianti J.M. (2001). Parteiras, médicos e enfermeiras: a disputada arte de partejar- Rio de Janeiro1934/1951. Rio de Janeiro (RJ): Escola de Enfermagem Anna Nery/ UFRJ.

Reich, E. (1998).Energia vital pela bioenergética suave. São Paulo: Summus.

Ribeiro, J.P. (2006). VadeMécum da Gestalt-terapia: conceitos básicos.São Paulo: Summus.

Rohden, F. (2003) Fragmentos da história da medicalização do parto: da indecência moral ao domínio médico. Fundação Oswaldo Cruz. Disponível em: http://www.coletiva.org/site/ index.php?option $=\mathrm{com}$ k2\&view $=$ item\&i$\mathrm{d}=139$ :fragmentos-da-hist\%C3\%B3ria-da-medicaliza\%C3\%A7\%C3\%A3o-do-parto-da-indec\%C3\%AAncia-moral-ao-dom\%C3\%ADnio-m\%C3\%A9dico\&tmpl=component\&print $=1$

Santos, D. S. \& Nunes, I. M. (2009). Doulas na assistência ao parto: concepção de profissionais de enfermagem. Esc. Anna Nery, Rio de Janeiro , 13(3), 582-588.

Serruya,S.J., Lago, T.G. \& Cecatti, J.G. O panorama da atenção pré-natal no Brasil e o Programa de Humanização do Pré-natal e Nascimento. Rev. Bras. Saúde Matern. Infantil, 4 (3), 269-279.

Stevens, J. O. (1997). Isto é Gestalt. São Paulo: Summus.

Teles, L. M. R., Pitombeira, H. C. S., Oliveira, A. S., Freitas, L. V.; Moura, E. R. F. \& Damasceno, A. K. C.(2010).Parto com acompanhante e sem acompanhante: a opinião das puérperas. Cogitare Enferm, 15(4) , p.688- 694.

Tostes, N. A. (2012). Percepção de gestantes acerca da assistência pré-natal, seus sentimentos e expectativas quanto ao preparo para o part. (Dissertação de Mestrado em Psicologia da Saúde). Universidade de Brasília, Brasília. 
Vargens O.M.C., Silva, A. C. V., Reis, C. S. C. \&Progianti, J.M. (2013). O emprego de práticas intervencionistas nos partos hospitalares acompanhados por enfermeiras obstétricas: uma análise contextual da medicalização x humanização [Resumo]. In Associação Brasileira de Enfermagem (org.), Resumos de comunicações científicas, $17^{\circ}$ Seminário Nacional de Pesquisa em Enfermagem (p. 1-3). Brasilia: ABEN.

Maiumi Souza Cruz Ferreira (orcid.org/0000-00016597-2714). Discente do Instituto de Gestalt-terapia da Bahia (IGTBa), Salvador - BA. Brasil. E-mail: maiumi.psicologia@gmail.com

Priscila de Lima Silva (orcid.org/0000-0002-30584727). Docente do Centro Universitário Jorge Amado (UNIJORGE), Salvador - BA. Brasil. E-mail: priscilalima30@gmail.com

Vanderson Barreto Pereira (orcid.org/0000-00032120-8444). Discente do Instituto de Gestalt-Terapia daBahia(IGTBa).Brasil.E-mail:vandersonbarreto5@ $\underline{\text { hotmail.com }}$

Recebido em 15.08.18

Primeira decisão editorial em 13.02.19

Segunda decisão editorial 31.07.19

Aceito em 17.12.19 